\title{
Chronic paroxysmal hemicrania: the first possible bilateral case
}

\author{
Walter Pöllmann, Volker Pfaffenrath
}

CEPHALALGIA

Pöllmann W, Pfaffenrath V. Chronic paroxysmal hemicrania: the first possible bilateral case.
Cephalalgia 1986;6:55-57. Oslo. ISSN 0333-1024

There are three headaches syndromes that are typically characterized by strictly unilateral and always same-sided attacks: cluster headache, "cervicogenic" headache, and chronic paroxysmal hemicrania $(\mathrm{CPH})$. In rare cases, cluster headache also occurs bilaterally; "cervicogenic" headaches probably as well. We present a patient with a probable bilateral CPH. To our knowledge no such case has previously been described. $\square$ Bilateral symptoms, chronic paroxysmal hemicrania, cluster headache

Walter Pöllmann, Volker Pfaffenrath, Neurologic Clinic of the Ludwig-Maximilians University Munich, Klinikum Grosshadern, Marchioninistrasse 15, D-8000 Munich 70, FRG; Accepted 16 December 1985

Since chronic paroxysmal hemicrania $(\mathrm{CPH})$ was first described by Sjaastad and Dale in 1974 (1), about 80 cases have been reported. We recently presented the first four cases to be diagnosed in Germany (2), one being an episodic case.

The full-blown clinical picture of $\mathrm{CPH}$ is characterized by daily, strictly unilateral attacks, which are confined to one side and show an absolute response to indomethacin $(1,3)$. Besides $\mathrm{CPH}$, cluster headache and "cervicogenic" headache are also marked by unilaterality of the attacks. Bilateral cluster headache attacks have been described in the literature; Sjaastad reported 1 case in 175 cluster headache patients (4), and Graham (cited in Ref. 4) observed 3 in 600. It is surmised that "cervicogenic" headache (5) also may occur bilaterally.

Recently, we encountered a patient presenting with a headache syndrome meeting the usual criteria of $\mathrm{CPH}$; however, the attacks were localized bilaterally.

\section{Case report}

The patient is female, 67 years old, retired, and a former sales assistant. In 1939 and 1962 she underwent lymph node extirpation under suspicion of tuberculosis and in 1981 hysterectomy. In 1982 she was operated on for an autonomous adenoma of the thyroid gland. There was no family history of headaches. Before the occurrence of the present headache she had never suffered from headaches. In January 1984, without any recognizable cause, the patient began to experience sudden occipital headaches. The pain had an intense, piercing quality and radiated to the temporal area, bilaterally from the beginning. The attacks lasted several seconds. Initially, the attacks occurred two to five times during the daytime, with symptoms at night after 10 months. In the course of some months, their frequency increased to 5 to 10 per $24 \mathrm{~h}$, the average duration of the individual attack being 5-8 min. The patient reported no physical triggering of the attacks, which then occurred generally at 1to 2-h intervals, sometimes with clocklike regularity. The onset was abrupt, with no premonitory signs, and they ceased as suddenly as they began. Between attacks the patient was completely free of complaints. On no occasion were accompanying symptoms reported, such as ptosis, miosis, conjunctival injection, lacrimation, facial pallor or reddening, sensitivity to noise and light, nausea, vomiting, or visual disturbances. During the attacks, the patient grasped her head in both hands, rocked it back and forth, and attempted to massage the painful sites in the nape of the neck. 


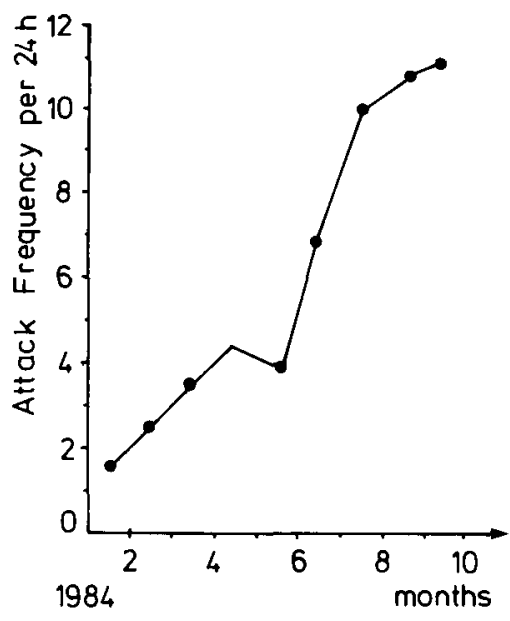

Fig. 1. Average attack frequency per $24 \mathrm{~h}$ from January to October 1984 without medication.

Fig. 1 gives a monthly survey of the mean 24-h attack frequency since January 1984.

The administration of $500 \mathrm{mg}$ of acetylsalicylic acid resulted in an approximately $50 \%$ reduction in the attack frequency (Fig. 2).

We first saw the patient in November 1984. At that time, she had an average of 5 to 7 headache attacks every $24 \mathrm{~h}$, with a maximum of 12 . The spontaneous attacks, several of which we were able to observe, occurred without external cause and were accompanied by neither visual nor autonomic symptoms and signs. Neurologic examination yielded no unusual findings. Trigger points, particularly at the $\mathrm{C} 2$ level, could not be demonstrated. Blood pressure during the attacks (around 155/90 $\mathrm{mm} \mathrm{Hg}$ ) was unchanged from that during the attack-free interval. It was not possible to provoke attacks with nitroglycerin (Nitrolingual ${ }^{\circledR}$ ). The inhalation of $71 / \mathrm{min}$ of $100 \%$ oxygen through a face mask for $15 \mathrm{~min}$ had no effect.

No unusual findings were noted in computer tomography scans including the craniocervical region, rCBF studies between the attacks, radiograms of the skull, cervical spine, and nasal sinuses, EEG, and bilateral somatosensory and auditory-evoked potentials.

The administration of $50 \mathrm{mg}$ of indomethacin in suppository form resulted in complete cessation of the attacks within $24 \mathrm{~h}$. After withdrawal of indomethacin, the attacks re-appeared within $19 \mathrm{~h}$, now regularly occurring in the early morning hours. It proved possible to reproduce the positive indomethacin effect repeatedly, with complete cessation of the attacks within 24 to $48 \mathrm{~h}$ and with recurrence of the attacks after discontinuation of the medication (Fig. 2). Indomethacin doses of $12.5 \mathrm{mg} /$ day were not sufficient to bring about complete remission.

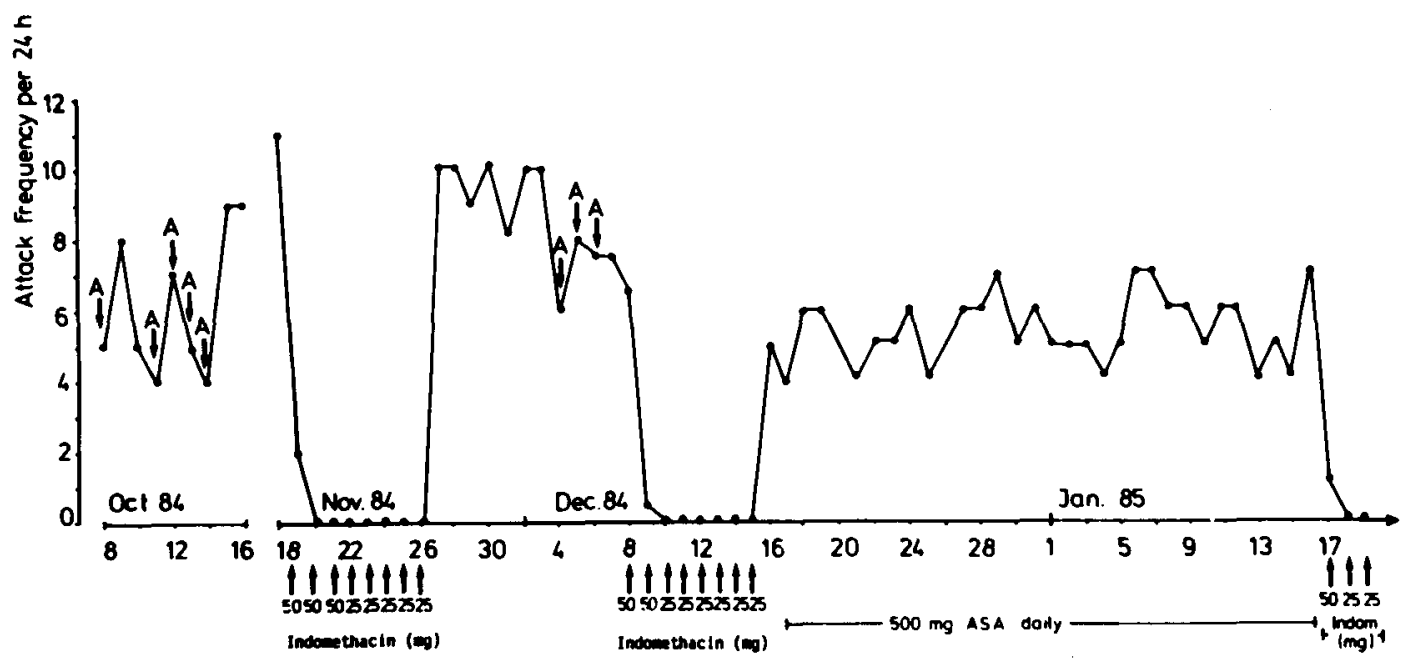

Fig. 2. Bilateral CPH: attack frequency during treatment with acetylsalicylic acid $(500 \mathrm{mg} /$ day) (A) and indomethacin. 


\section{Discussion}

The case presented involves a headache syndrome having most of the typical symptoms of $\mathrm{CPH}$ with regard to the nature of the pain, attack frequency, duration of individual attacks, and prompt and complete response to indomethacin $(6,7)$.

To our knowledge no case of bilateral $\mathrm{CPH}$ has yet been described. In our patient a primary chronic course without a foregoing pre-CPH stage (8) may be inferred.

Autonomic signs and the excruciating quality of the pain, which are common to cluster headaches and most cases of $\mathrm{CPH}$, were lacking, which may be because the symptoms have not yet completely developed (early CPH-stage?). In addition to the bilaterality, the occipito-temporal radiation of the pain without typical orbital pain maximum is noteworthy and makes one hesitant with regard to the correct diagnosis.

In the early stage of $\mathrm{CPH}$, acetylsalicylic acid may be effective $(6,9)$, without producing complete remission of the symptoms. The mechanism of action of indomethacin, the unique efficacy of which is pathognomonic of $\mathrm{CPH}$, is not known. Given to our patient in sufficient doses, indomethacin led to complete suppression of attacks.

The etiology and pathogenesis of $\mathrm{CPH}$ are only partly known. Investigations have led to the assumption that the attacks are associated with enhanced sympathetic activity (10); the pain, however, arises through a still unknown mechanism. Even though some doubts remain as to the correct diagnosis, it is hoped that the present case report will contribute to the discussion of the pathogenesis of $\mathrm{CPH}$.

\section{References}

1. Sjaastad O, Dale I. Evidence for a new (?) treatable headache entity. Headache 1974;14:105-8

2. Pfaffenrath V, Kufner G, Pöllmann W. Die chronisch paroxysmale Hemicranie (CPH). Nervenarzt 1984;55:402-6

3. Sjaastad O, Dale I. A new (?) clinical headache entity 'chronic paroxysmal hemicrania'. Acta Neurol Scand 1976;54:140-59

4. Sjaastad O, Saunte C, Frederiksen TA. Bilaterality of cluster headache. An hypothesis. Cephalalgia $1985 ; 5: 55-8$

5. Sjaastad O, Saunte C, Hovdahl H, Breivik H, Grönbaek E. 'Cervicogenic' headache. An hypothesis. Cephalalgia 1983;3:249-56

6. Russell D, Sjaastad O. Chronic paroxysmal hemicrania $(\mathrm{CPH})$. Diagnosis and treatment. In: Pfaffenrath V, Sjaastad O, Lundberg PO eds Updating in headache. Berlin: Springer 1985;1-6

7. Sjaastad O, Apfelbaum R, Caskey $W$, Christoffersen B, Diamond S, Graham J, Green M, Hørven I, Lund-Roland L, Medina J, Rogado S, Stein $\mathrm{H}$. Chronic paroxysmal hemicrania (CPH): the clinical manifestations. A review. Ups J Med Sci 1980;31(suppl):27-33

8. Bogucki A, Szymanska R, Braciak W. Chronic paroxysmal hemicrania: lack of pre-chronic stage. Cephalalgia 1984;4:187-9

9. Price RW, Posner JB. Chronic paroxysmal hemicrania: a disabling headache syndrome responding to indomethacin. Ann Neurol 1978;3:183-4

10. Sjaastad O, Saunte C, Russell D. Chronic paroxysmal hemicrania ( $\mathrm{CPH}$ - - a treatable headache entity with a partly known pathogenesis. Neuropsychiatr Clin 1983;2:79-85 